\title{
Pseudomonas Quinolone Signal Modulates Cystic Fibrosis Epithelial Cell Response through the Toll- Like Receptor 4
}

\author{
Patricia R. Wardwell ${ }^{1,2}$, David R. Wilson ${ }^{1,2}$, Dewayne L. Garner ${ }^{1,2}$ and Rebecca A. Bader ${ }^{1,2 *}$ \\ ${ }^{1}$ Department of Biomedical \& Chemical Engineering, Syracuse Biomaterials Institute, Syracuse University, Syracuse, NY, USA \\ ${ }^{2}$ Onondaga Community College, Syracuse, NY, USA
}

\begin{abstract}
Received: March 06, 2015; Accepted: March 26, 2015; Published: April 07, 2015
*Corresponding author: Rebecca A. Bader, Department of Biomedical \& Chemical Engineering, Syracuse Biomaterials Institute, Syracuse University, Syracuse, NY, USA, Tel: +13154439709; Fax: +13154437724; E-mail: babader@syr.edu
\end{abstract}

\begin{abstract}
Pseudomonas aeruginosa is an opportunistic human pathogen that causes severe infection in compromised individuals, including persons with Cystic Fibrosis (CF). The expression of many virulence factors in P. aeruginosa is controlled by Quorum Sensing Molecules (QSMs) that are synthesized and secreted by this bacterium. Recent studies suggest that QSMs are also capable of interspecies communication, with exposure of mammalian cells to Acyl-Homoserine Lactones (AHLs) and Pseudomonas Quinolone Signal (PQS) resulting in an immunomodulatory response. Although the initial immune response is intended to clear/contain the infection, this process is ineffective in $\mathrm{CF}$ lungs, and the persistent, excessive inflammation eventually leads to structural damage to the tissue. The goal of this study was to examine the response of IB3-1 CF airway epithelial cell line to PQS, alone and in conjunction with Pseudomonas-Derived Lipopolysaccharides (pLPS). In contrast to results obtained with other cell types suggesting that PQS is anti-inflammatory, PQS induced inflammation in the IB3$1 \mathrm{CF}$ cell line and exacerbated inflammation when administered simultaneously with LPS, as determined by ELISA for two markers of inflammation, interleukin-6 and interleukin-8. In addition, PQS was shown, for the first time, to act through toll-like receptor 4 , a receptor that traditionally has only been associated with LPS. A better understanding of the role that QSMs play in the inflammatory response can potentially lead to new strategies to minimize airway destruction.
\end{abstract}

Keywords: Pseudomonas aeruginosa; Pseudomonas lipopolysaccharides; Pseudomonas quinolone signal; Cystic fibrosis; Epithelial cells

\section{oIntroduction}

Pseudomonas aeruginosa is an opportunistic human pathogen that causes a wide range of infections in compromised individuals [1]. In Cystic Fibrosis (CF) patients, P. aeruginosa is the most prevalent bacteria to colonize the lungs and is significantly correlated with increase in morbidity and mortality [2]. The treatment of $\mathrm{CF}$ is complicated by the resistance of $P$. aeruginosa to a number of antibiotic treatments, due in part to the formation of thick, mucoid biofilms [2]. Additional difficulties in the treatment of the $P$. aeruginosa infection in CF lungs arise from chronic inflammation resultant from a dysregulated innate immune response. Early stages of infection are hallmarked by the presense of neutrophils intended to clear the infection; however, the process is not adequate in CF lungs, and the persistent inflammation leads to severe, structural tissue damage [3]. In healthy lung tissue, the resident epithelial cells serve as a protective barrier; in contrast, with $\mathrm{CF}$, these epithelial cells are thought to serve as the originators for the proinflammatory signaling that is perpetuated by bacteria-derived stimuli.

Indirect and direct interactions between the bacteria and host cells serve to promote infection and inflammation. For example, bacterial Quorum Sensing (QS) molecules, which regulate the expression of genes associated with virulence factor production, biofilm formation, and antibotic resistance, have been shown to play a critical role in inter-kingdom signaling. Two QS systems in $P$. aeruginosa are based upon the interaction of $\mathrm{N}$-acylhomoserine lactones (AHLs), specifically $\mathrm{N}$-(3-oxododecanoyl) Homoserine Lactone (3-oxo- $\mathrm{C}_{12}$ - $\mathrm{HSL}$ ) and N-butyryl Homoserine Lactone $\left(\mathrm{C}_{4}-\mathrm{HSL}\right)$, with inducible transcription factors, LasR and $\mathrm{RhIR}$, respectively, that activate gene expression [4]. Another, lesser studied, QS system relies upon the association of 2-heptyl3-hydroxy-4-quinolone, referred to as Pseudomonas Quinolone Signal (PQS), with PqsR [5]. Although the primary role of QS molecules is to control gene expression by P. aeruginosa, these molecules also elicit a response from host cells $[6,7]$.

In general,AHLs are thoughtto modulate the immune response in a concentration dependent manner with low concentrations $(<10 \mu \mathrm{M})$ reducing the production of inflammatory mediators and higher concentrations activating pro-inflammatory signaling

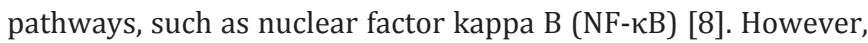
the exact nature of the immunomodulatory impact further depends on the structure of the AHL [9], the presence of additional bacteria-derived stimuli (especially lipopolysaccharides, LPS) [10], and the type of mammalian cell [11]. The structurally distinct $\mathrm{PQS}$ molecule has likewise given rise to a mixture of seemingly conflicting results. At non-cytotoxic concentrations (1-5 $\mu \mathrm{M})$, administration of PQS to monocytes and bronchoalveolar cells 
resulted in a reduction in the secretion of two pro-inflammatory mediators, tumor necrosis factor- $\alpha$ (TNF- $\alpha$ and interleukin-6 (IL$6)$, purportedly via suppression of the NF- $\kappa B$ pathway. However, administration of high concentrations of $\mathrm{PQS}(\geq 10 \mu \mathrm{M})$ resulted in enhanced TNF- $\alpha$ secretion [6]. Feasibly, the QSMs act in concert to ensure that the innate immune response required for removing bacteria is impaired while maintaining the proinflammatory environment that yields structural damage.

The gap in knowledge regarding the precise role of QSMs, particularly $\mathrm{PQS}$, in the dysregulation of the host inflammatory response highlights the need for further research on the complexity of inter-kingdom signaling. Towards this end, our lab has been working towards understanding of the role that PQS plays in modulating the inflammatory response, particularly as pertains to the profoundly altered, CF airway epithelial cells. In this study, ELISA was used to assess changes in the secretion of two proinflammatory mediators, Interleukin-6 (IL-6) and Interleukin-8 (IL-8,) by the IB3-1 CF epithelial cell line resultant from treatment with combinations of LPS derived from $P$. aerugnosa, $\mathrm{pLPS}$, and $\mathrm{PQS}$. The selected proteins are known to be elevated in patients with CF [12]. In addition, pleiotropic IL-6 serves as a key player in the overall immune response [13], while IL-8 is active in the recruitment of neutrophils that have been directly linked to reduced pulmonary function and increased lung damage $[14,15]$. To further understand how PQS interacts with the host cell, identical experiments were conducted following treatment of cells with toll-like receptor 4 antibody (TLR4-pAB). Toll like receptors are a family of transmembrane cell receptors that recognize bacteria and other microorganisms, with TLR4 serving as a receptor for Gram-negative lipopolysaccharides [16]. Although AHLs have been shown to induce a cellular response through a mechanism that does not involve the TLRs, the interaction of PQS with TLRs has not previously been studied.

\section{Materials and Methods}

\section{Cell culture and cytotoxicity}

IB3-1 CF epithelial cells were obtained from Professor Pam Zeitlin at Johns Hopkins University and cultured at $37^{\circ} \mathrm{C}, 5 \% \mathrm{CO}_{2}$ in LHC-8 complete growth media (Invitrogen), supplemented with $5 \%$ fetal bovine serum (Atlanta Biologics) on $25 \mathrm{~cm}^{2}$ collagencoated tissue culture flasks. pLPS and PQS were procured from Sigma Aldrich. Cytotoxicity of PQS (0-200 $\mu \mathrm{g} / \mathrm{ml}$ ) and pLPS $(0-1000 \mu \mathrm{g} / \mathrm{ml})$ towards the IB3-1 cells was assessed using a WST-8 cell proliferation assay (Cayman Chemical) following the manufacturer's instructions.

\section{Immunomodulation by PQS and pLPS}

Media for stimulation of the IB3-1 cells was prepared via dilution of pLPS and PQS stock solutions in DMSO at $5 \mathrm{mg} / \mathrm{mL}$ and $10 \mathrm{mg} / \mathrm{mL}$, respectively. The DMSO did not have an impact on cellular proliferation at such low concentrations within the media. Upon reaching confluence within the $25 \mathrm{~cm}^{2}$ tissue culture plates, the cells were seeded into coated 24 well plates at a density of 25,000 cells per well in $500 \mu \mathrm{L}$ of media. Plated cells were allowed to adhere for $24 \mathrm{~h}$ in unstimulated media, at which point the media was replaced with $500 \mu \mathrm{L}$ of stimulated media containing various combinations of pLPS and PQS. After $24 \mathrm{~h}$, the supernatant was collected and stored at $-80^{\circ} \mathrm{C}$ until analysis.

\section{Toll-like receptor 4 blocking}

LPS is known to induce inflammation through complexation with TLR4 [16]. To identify if TLR4 also plays a role in the host cell response to $\mathrm{PQS}$, cells were seeded into a 24 well plate, as described above. At $23 \mathrm{~h}$ after seeding, the media was replaced with LHC-8 media with 5\% FBS and $1 \mu \mathrm{g} / \mathrm{mL}$ of TLR4- pAB (Santa Cruz Biotechnology). After 1h of exposure to the TLR4$\mathrm{pAB}$, the media was removed and replaced with media containing combinations of pLPS and/or PQS with $1 \mu \mathrm{g} / \mathrm{mL}$ TLR4-pAB. After $24 \mathrm{~h}$, the supernatant was collected and stored at $-80^{\circ} \mathrm{C}$ until analysis. In additional studies to confirm the role of TLR4 in $\mathrm{PQS}$ interactions, cells were treated with $1 \mu \mathrm{g} / \mathrm{mL}$ of IgG isotype control antibody prior to stimulation with either PQS alone (10 $\mu \mathrm{g} / \mathrm{mL})$ or in combination with pLPS $(100 \mu \mathrm{g} / \mathrm{mL})$.

\section{Quantitative analysis of inflammatory cytokines}

IL-6 and IL-8 ELISA kits (Peprotech) were run according to the manufacturer's instructions to determine the levels of IL-6 and IL-8 in the collected supernatant. Samples were run in duplicate, and each experiment was repeated independently at least three times.

\section{Statistical analysis}

All data is expressed as the mean \pm the standard deviation. IL- 6 and IL-8 levels were expressed relative to cells that remained untreated. To compare cytokine profiles obtained from exposure of the cells to various stimulant combinations, with or without TLR4-pAB, one-way ANOVA with Fisher's LSD post-hoc test was performed. For each combination of stimulants, the Student's t-test was used to compare IL- 6 and IL-8 concentrations with and without TLR4-pAB. Student's t-test was likewise used to compare IL-6 and IL-8 concentrations for cells treated with TLR4-pAB and isotype control antibody. Differences were considered to be significant when $p \leq 0.05$.

\section{Results and Discussion \\ Cytotoxicity of PQS and pLPS}

Both pLPS and PQS were found to be non-cytotoxic towards the IB3-1 cells over the majority of concentrations observed (Figure 1). The lack of PQS cytotoxicity is consistent with results obtained previously by other investigators $[17,18]$. In accord with the observed outcome in this study, LPS derived from $P$. aeruginosa is less cytotoxic than that derived from Escherichia coli and other enterobacterial species, purportedly due to differences in the structure of the bisphosphorylated lipid (lipid A) component of the molecule. Structural changes in Lipid A may likewise cause an enhanced inflammatory response. In general, an increase in the degree of acylation from a penta-acylated form to hexa- or hepta-acylated form is directly correlated to the production of pro-inflammatory mediators $[19,20]$.

\section{Immunomodulation by PQS and pLPS through toll-like receptor 4}

As anticipated, stimulation with pLPS alone enhanced the 
secretion of pro-inflammatory mediators by the IB3-1 epithelial cells, although the increase in IL-6 was not significant (Figure 2). Cellular activation by pLPS is thought to occur by binding to CD14, followed by interaction with TLR4 and co-factor MD-2 [16]. Interaction with TLR4 in turn leads to the recruitment of Myeloid Differentiation Primary Response Gene 88 (MyD88) adapter protein through interaction with the TIR (Toll-Interleukin-1 Receptor) domain, which subsequently stimulates the production of proinflammatory mediators through activation of the NF-kB and Mitogen-Activated Protein Kinase (MAPK) pathways [21-23]. A number of seemingly contradictory reports exist pertaining to the location of TLR4 on lung epithelial cells [24]. In the current study, the addition of TLR4-pAB resulted in reduced secretion of IL- 6 and IL- 8 when the cells were stimulated by pLPS, regardless of the presence of $\mathrm{PQS}$. The latter result strongly indicates that pLPS-induced activation occurs at TLR4 on the cell surface.
Stimulation with PQS alone yielded a trend towards increased secretion of IL- 6 and IL-8. These results contrast reports that $\mathrm{PQS}$ possesses anti-inflammatory properties [6] (Figure 2). However, to our knowledge, all prior studies were conducted with lymphocytes or phagocytes, suggesting that impact of PQS may be cell-type dependent, as has been previously observed for AHLs. For example, at $10 \mu \mathrm{M}, 3$-oxo- $\mathrm{C}_{12}$-HSLreduced the secretion of Interleukin-12 (IL-12), a pro-inflammatory cytokine, by LPSstimulated macrophages [10], while exposure of lung fibroblasts and epithelial cells to the same concentration, without an additional stimulant, enhanced the secretion of IL-8 [11]. Thus, PQS may effectively mirror AHLs in regards to inter-kingdom signaling.

Together, PQS and LPS acted in a synergistic manner, as indicated by increased IL- 6 and IL- 8 relative to levels obtained with either mediator alone. Surprisingly, blocking the TLR4

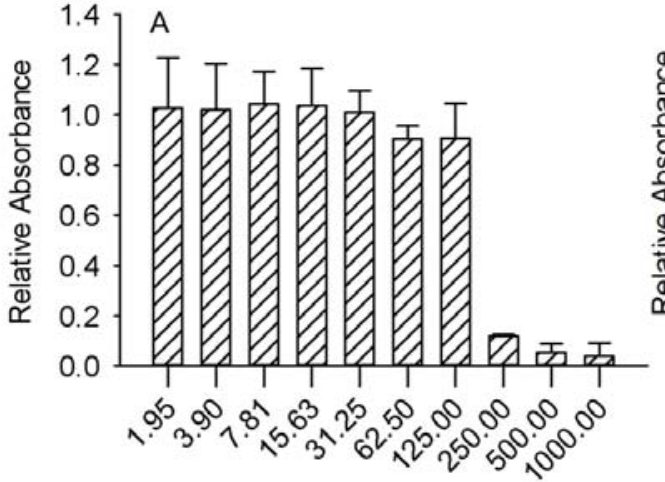

pLPS Concentration $(\mu \mathrm{g} / \mathrm{mL})$

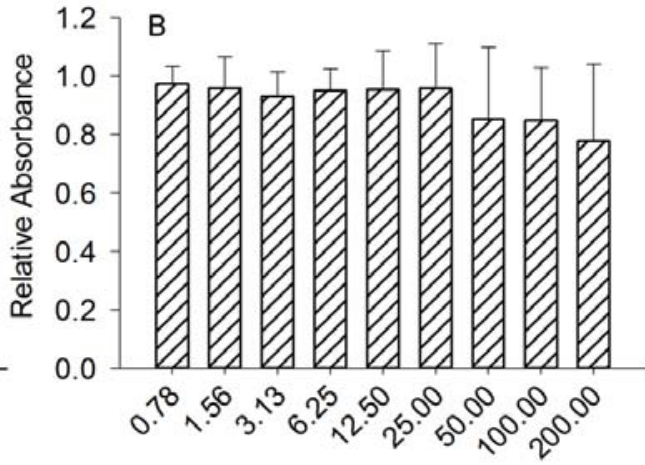

PQS Concentration $(\mu \mathrm{g} / \mathrm{mL})$

Figure 1: Increasing pLPS concentrations were non-cytotoxic towards the IB3-1 cells up to $125 \mu \mathrm{g} / \mathrm{ml}$ (A), while increasing PQS concentrations had no significant impact on cellular viability over the range of concentrations observed (B).
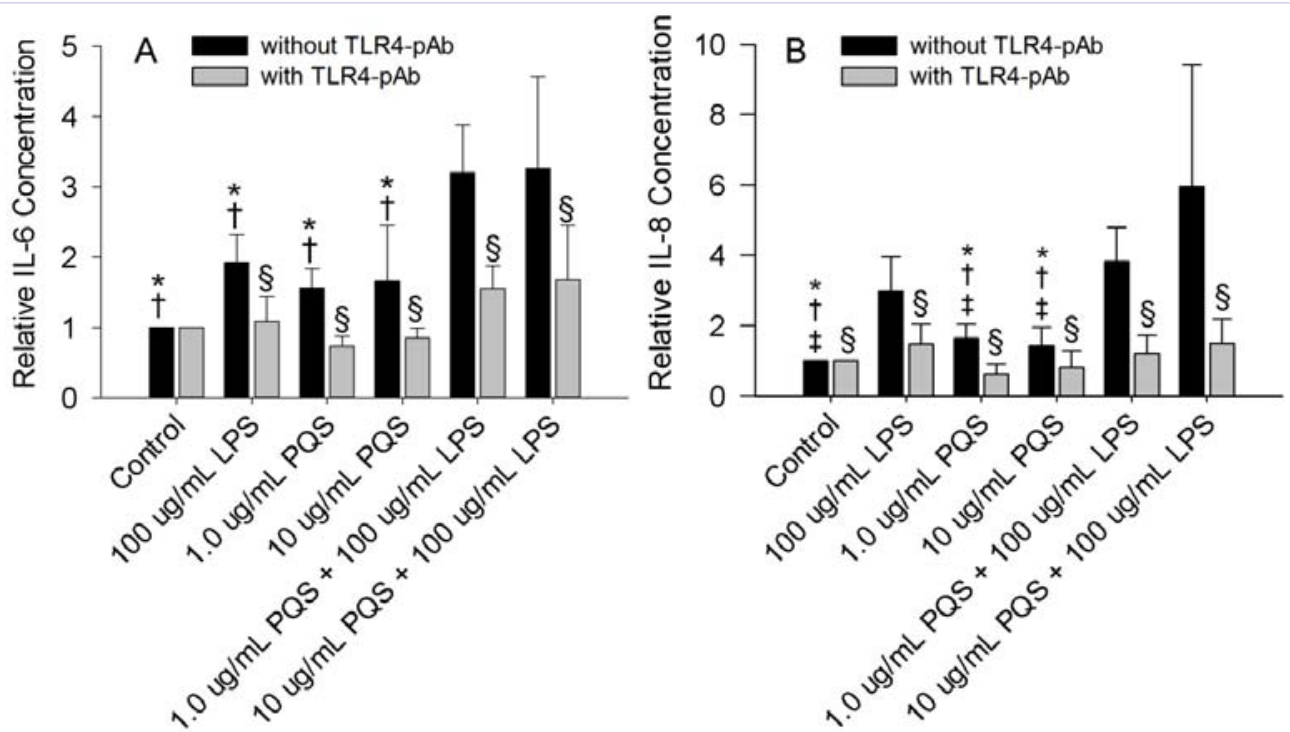

Figure 2: ELISA was performed to determine the levels of IL-8 (A) and IL-6 (B) secretion after stimulation with pLPS and/or PQS for 24 hours in the presence $(\square)$ or absence $(\square$ of TLR4-pAB. Results are expressed as fold changes relative to a non-stimulated control. All data is presented as mean $\pm \mathrm{SD}(\mathrm{N}=3)$. ${ }^{*}, \mathrm{p}<0.05$ versus $1.0 \mu \mathrm{g} / \mathrm{ml} \mathrm{PQS}+100 \mu \mathrm{g} / \mathrm{ml} \mathrm{LPS} ; \neq, \mathrm{p}<0.05$ versus $100 \mu \mathrm{g} / \mathrm{ml} \mathrm{LPS} ; \dagger, \mathrm{p}<0.05$ versus $10 \mu \mathrm{g} / \mathrm{ml} \mathrm{PQS}+100 \mu \mathrm{g} / \mathrm{ml} \mathrm{LPS}$, and $\S, \mathrm{p}<0.05$ versus the corresponding stimulation condition without TLR4 blocking. 

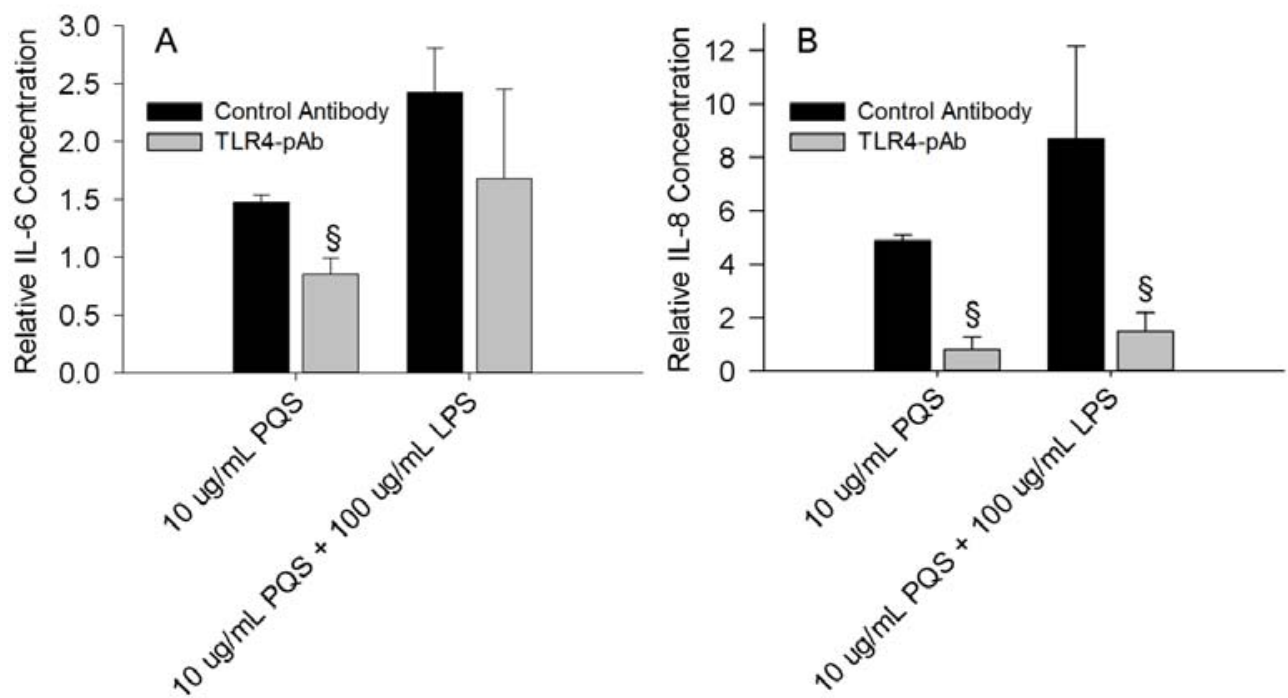

Figure 3: ELISA was performed to determine the levels of IL-8 (A) and IL-6 (B) secretion after stimulation with PQS alone or in combination with

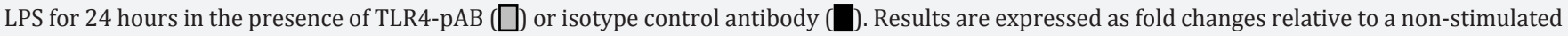
control. All data is presented as mean $\pm \mathrm{SD}(\mathrm{N}=3)$. $\S, \mathrm{p}<0.05$ versus the corresponding stimulation condition with isotype control antibody blocking.

receptor reduced secretion of IL- 6 and IL-8 when cells were subsequently stimulated by $\mathrm{PQS}$, regardless of the presence of pLPS. To confirm the latter result, cells treated with the TLR4$\mathrm{pAB}$ or isotype control antibody prior to stimulation with PQS alone or in combination with pLPS were compared (Figure 3). The TLR4-pAB antibody significantly reduced cytokine secretion relative to any changes that resulted from non-specific antibody binding; thereby, supporting the notion that $\mathrm{PQS}$ interacts with TLR4. A similar technique has been used previously to validate that $P$. aeruginosa induces a cellular response through interaction with TLR5 [25]. Although LPS is known to act through TLR4 [16], this is the first report of $P Q S$ interacting with a tolllike receptor. Subsequent studies will explore (1) whether PQS interacts directly with TLR4 or requires prior complexation with other membrane proteins and (2) if PQS activates the NF-kB and MAPK proinflammatory signaling pathways through recruitment of MyD88, as occurs with pLPS.

In conclusion, through improved understanding of interkingdom signaling and the factors involved in Immunomodulation, more effective treatment strategies for diseases associated with infection and inflammation can be designed. For the first time, we demonstrated that PQS acts through TLR4 and can act synergistically with pLPS to enhance the inflammatory response. Future studies will aim towards garnering further understanding of the mechanism by which PQS interacts with TLR4 and activates proinflammatory pathways. In addition, this study paves the way for future studies on inter-kingdom signaling linked to other structurally similar Quinolone, such as the PQS precursor 4-Hydroxy-2-Heptyl quinoline (HHQ) that are released by $P$. aeruginosa [26,27].

\section{References}

1. Bjarnsholt T, Jensen PO, Jakobsen TH, Phipps R, Nielsen AK, Rybtke MT, et al. Quorum sensing and virulence of Pseudomonas aeruginosa during lung infection of cystic fibrosis patients. PLoS One. 2010; 5(4): e10115. doi: 10.1371/journal.pone.0010115.

2. Deretic V, Govan JR, Konyecsni WM, Martin DW. Mucoid Pseudomonas aeruginosa in cystic fibrosis: mutations in the muc loci affect transcription of the algR and algD genes in response to environmental stimuli. Mol Microbial. 1990; 4(2): 189-196.

3. Rieber N, Hector A, Carevic M, Hartl D. Current concepts of immune dysregulation in cystic fibrosis. Int J Biochem Cell Biol. 2014; 52: 108112. doi: 10.1016/j.biocel.2014.01.017.

4. Passador L, Cook JM, Gambello MJ, Rust L, Iglewski BH. Expression of Pseudomonas aeruginosa virulence genes requires cell-to-cell communication. Science. 1993; 260(5111): 1127-1130.

5. Pesci EC, Milbank JB, Pearson JP, McKnight S, Kende AS, Greenberg EP, et al. Quinolone signaling in the cell-to-cell communication system of Pseudomonas aeruginosa. Proc Natl Acad Sci USA. 1999; 96(20): 11229-11234.

6. Kim K, Kim YU, Koh BH, Hwang SS, Kim SH, Lépine F, et al. HHQ and $\mathrm{PQS}$, two Pseudomonas aeruginosa quorum-sensing molecules, down-regulate the innate immune responses through the nuclear factor-kappa B pathway. Immunology. 2010; 129(4): 578-588. doi: 10.1111/j.1365-2567.2009.03160.x.

7. Reen FJ, Mooij MJ, Holcombe LJ, McSweeney CM, McGlacken GP, Morrissey JP, et al. The Pseudomonas quinolone signal (PQS), and its precursor $\mathrm{HHQ}$, modulate interspecies and interkingdom behaviour. FEMS Microbiol Ecol, 2011; 77(2): 413-428. doi: 10.1111/j.15746941.2011.01121.x.

8. Cooley M, Chhabra SR, Williams P. N-Acylhomoserine lactonemediated quorum sensing: a twist in the tail and a blow for host immunity. Chem Biol. 2008; 15(11): 1141-1147. doi: 10.1016/j. chembiol.2008.10.010.

9. Davis BM, Jensen R, Williams P, O'Shea P. (2010). The interaction of $\mathrm{N}$-acylhomoserine lactone quorum sensing signaling molecules with biological membranes: implications for inter-kingdom signaling. PLoS One. 2010; 5(10): e13522. doi: 10.1371/journal.pone.0013522.

10. Telford G, Wheeler D, Williams P, Tomkins PT, Appleby P, Sewell H, 
et al. The Pseudomonas aeruginosa quorum-sensing signal molecule $\mathrm{N}$-(3-oxododecanoyl)-L-homoserine lactone has immunomodulatory activity. Infect Immun. 1998; 66(1): 36-42.

11.Smith RS, Fedyk ER, Springer TA, Mukaida N, Iglewski BH, Phipps RP. IL-8 production in human lung fibroblasts and epithelial cells activated by the Pseudomonas autoinducer N-3-oxododecanoyl homoserine lactone is transcriptionally regulated by NF-kappa B and activator protein-2. J Immunol. 2001; 167(1); 366-374.

12. Elizur A, Cannon CL, Ferkol TW. Airway inflammation in cystic fibrosis. Chest. 2008; 133(2): 489-495. doi: 10.1378/chest.07-1631.

13. Rincon M, Irvin CG. Role of IL-6 in asthma and other inflammatory pulmonary diseases. Int J Biol Sci. 2012; 8(9): 1281-1290. doi: $10.7150 /$ ijbs. 4874

14. Bonfield TL, Panuska JR, Konstan MW, Hilliard KA, Hilliard JB, Ghnaim $\mathrm{H}$, et al. Inflammatory cytokines in cystic fibrosis lungs. Am J Respir Crit Care Med. 1995; 152(6): 2111-2118.

15. Downey DG, Bell SC, Elborn JS. Neutrophils in cystic fibrosis. Thorax. 2009; 64(1): 81-88.

16. Miller SI, Ernst RK, Bader MW. LPS, TLR4 and infectious disease diversity. Nat Rev Microbiol. 3(1): 36-46.

17. Skindersoe ME, Zeuthen LH, Brix S, Fink LN, Lazenby J, Whittall C, et al. Pseudomonas aeruginosa quorum-sensing signal molecules interfere with dendritic cell-induced T-cell proliferation. FEMS Immunol Med Microbiol. 2009; 55(3): 335-345. doi: 10.1111/j.1574695X.2008.00533.x.

18. Reen FJ, Clarke SL, Legendre C, McSweeney CM, Eccles KS, Lawrence $\mathrm{SE}$, et al. Structure-function analysis of the C-3 position in analogues of microbial behavioural modulators HHQ and PQS. Org Biomol Chem. 2012; 10(44): 8903-8910. doi: 10.1039/c2ob26823j.
19. Hajjar AM, Ernst RK, Tsai JH, Wilson CB, Miller SI. Human Toll-like receptor 4 recognizes host-specific LPS modifications. Nat immunol. 2002; 3(4): 354-359.

20. Ernst RK, Hajjar AM, Tsai JH, Moskowitz SM, Wilson CB, Miller SI. Pseudomonas aeruginosa lipid A diversity and its recognition by Tolllike receptor 4. J Endotoxin Res. 2003; 9(6): 395-400.

21. Chow JC, Young DW, Golenbock DT, Christ WJ, Gusovsky F. Toll-like receptor-4 mediates lipopolysaccharide-induced signal transduction. J Biol Chem. 1999; 274(16): 10689-10692.

22.Lu YC, Yeh WC, Ohashi PS. LPS/ TLR4 signal transduction pathway. Cytokine. 2008; 42(2): 145-151. doi: 10.1016/j.cyto.2008.01.006.

23. ?Warner N, Nunez G. MyD88: a critical adaptor protein in innate immunity signal transduction. J Immunol. 2013; 190(1): 3-4. doi: 10.4049/jimmunol.1203103.

24. Guillot L, Medjane S, Le-Barillec K, Balloy V, Danel C, Chignard M, et al. Response of human pulmonary epithelial cells to lipopolysaccharide involves Toll-like receptor 4 (TLR4)-dependent signaling pathways: evidence for an intracellular compartmentalization of TLR4. J Biol Chem. 2004; 279(4): 2712-2718.

25. Blohmke CJ, Victor RE, Hirschfeld AF, Elias IM, Hancock DG, Lane CR, et al. Innate immunity mediated by TLR5 as a novel antiinflammatory target for cystic fibrosis lung disease. J Immunol. 2008; 180(11): 7764-7773.

26. Lépine F, Milot S, Déziel E, He J, Rahme LG. Electrospray/ mass spectrometric identification and analysis of 4-hydroxy-2alkylquinolines (HAQs) produced by Pseudomonas aeruginosa. J Am Soc Mass Spectrom. 2004; 15(6): 862-869.

27. Mashburn LM, Whiteley M. Membrane vesicles traffic signals and facilitate group activities in a prokaryote. Nature. 2005; 437(7057): 422-425. 